\title{
Implementación Pedagogía Flipped Classroom adaptada para una modalidad semipresencial en una carrera técnico profesional
}

\section{Benjamín García Hulaud ${ }^{\text {a }}$ y Ana María Tello Ardemagni ${ }^{\text {b }}$}

${ }^{a}$ Subdirector Escuela Informática y Telecomunicaciones, Duoc UC, bgarcia@duoc.cl y , ${ }^{\mathrm{b}}$ Analista Curricular e Instruccional, Escuela de Informática y Telecomunicaciones, Duoc UC, atello@duoc.cl.

\begin{abstract}
This communication reviews the main challenges experienced by the School of Information Technology and Telecommunications of the Technical Professional Institute Duoc UC, Chile, while incorporating flexibility in their programs, formulating a blended format of the same curriculum traditionally offered. This challenge, brought a thorough review and critique of current teaching strategies curriculum of the school, and therefore decide to what should be the teaching strategy appropriate to the times and current context.

From that analysis, the ideation of a blended format considered a Flipped Classroom methodology, resulting in a model with features of self-learning supported in a virtual learning environment, which enhances the active and social learnings of the student through the Educational Technology available. In addition, it was reviewed the challenges of instructional production to fulfill this ideation, and academic results have been observed in students under this modality compared to students in traditional format using the same final assessment instruments at the end of the courses.
\end{abstract}

Keywords: Blended, Flipped Classroom, Flexibility

\section{Resumen}

La comunicación repasa los principales desafios que vivió la Escuela de Informática y Telecomunicaciones del Instituto Técnico Profesional Duoc UC, Chile, al incorporar la flexibilización en sus programas formulando una modalidad semipresencial de los mismos planes de estudio ofertados tradicionalmente. Este desafio, trajo consigo una revisión profunda y crítica acerca de las actuales estrategias de enseñanza de los programas de estudio de la Escuela, y en consecuencia tomar la decisión de cuál debiera ser la estrategia pedagógica adecuada a los tiempos y contexto actual.

De aquel análisis, la ideación de la modalidad semipresencial consideró una metodología Flipped Classroom, resultando en un modelo con características de autoaprendizaje soportado en un ambiente virtual de aprendizaje, el cual potencia el aprendizaje activo y social de los estudiantes a través de la Tecnología Educativa disponible. Además, se revisan los desafios que reviste la producción instruccional al servicio de esta ideación, y los resultados académicos que se han observado en los estudiantes bajo esta modalidad en comparación a los estudiantes en modalidad tradicional, a través de los mismos instrumentos evaluativos al finalizar las asignaturas.

Palabras clave: Semipresencial, Flipped Classroom, Flexibilidad

(cc) EY-NC-ND 2016, Universitat Politècnica de València 


\section{Introducción}

Duoc UC es una Fundación Privada fundada por la Pontificia Universidad Católica de Chile, por lo que participa de su vocación de servicio a la educación del país como Instituto Profesional y Centro de Formación Técnica, y además, como Institución de la Iglesia Católica cumple un rol evangelizador formando personas con una sólida base Ética inspirada en valores cristianos. Nuestro Modelo de Educación vigente desde el año 2004, pionero en el país, es un Modelo Basado en Competencias, por lo que el origen y propósito de nuestros Planes de Estudio responden directamente a Demandas del Mundo laboral.

Cabe enfatizar el carácter de masividad que tiene Duoc UC, el cual cuenta con más de 97 mil estudiantes en las 3 principales regiones de Chile en que mantiene presencia, distribuidos en 16 Sedes, 9 Escuelas y 82 Planes de Estudios. Cuenta con más 2.500 personas administrativas y directivas, más de 4.000 docentes y más de 220 mil m2 construidos. A su vez, la Escuela de Informática y Telecomunicaciones de Duoc UC cuenta con más de 11.000 estudiantes repartidos en 7 Planes de Estudios en 11 Sedes y más de 400 docentes de especialidad disciplinaria. Lo anterior, permite relevar el alcance que esta Innovación tiene para la Institución, la cual resguarda la respectiva alineación curricular, escalabilidad y mejoramiento continuo de sus programas.

La Escuela de Informática y Telecomunicaciones de Duoc UC, ha determinado como crítico para el logro de su misión, la flexibilización de los planes de estudio, razón por la cual ha resuelto la formulación de un plan de estudio en modalidad semipresencial.

Durante el 2013 la Escuela abordó el proyecto de implementación de la modalidad semipresencial, de tal forma de impartir el Plan de Estudios Analista Programador Computacional en esa modalidad desde el 2014 y Administración de Redes Computacionales desde el 2015. Ambas son carreras técnicas de 5 semestres con un fuerte enfoque práctico y centrado en contextos laborales propio del Modelo Educativo, el cual integra competencias disciplinarias y transversales (habilidades blandas) para dar cumplimiento a un perfil de egreso que a su vez responde a un perfil ocupacional determinado.

En primera instancia, este encargo se intentó resolver desde las lógicas y dinámicas que la Escuela mantenía vigentes en ese momento, centrando su innovación en el uso de una plataforma que brindara nuevas funcionalidades para el aprendizaje a distancia. Básicamente, se estaba subiendo al ambiente virtual de aprendizaje (AVA), la filmación de las clases teóricas en formato de video interactivo con el apoyo de una plataforma atractiva desde el punto de vista estético, con el fin de que el estudiante visualice esta clase en línea previa a su participación en la clase presencial. Rápidamente se observó un error en el prototipo resultante, el cual no permitía garantizar que el alumno se activaría en su proceso formativo sólo por ver filmaciones de una clase tradicional. Por lo anterior, nos vimos en la necesidad de indagar y prospectar otros modelos que fuesen más adecuados a los objetivos planteados. Así fue cómo se encontraron experiencias en la metodología denominada Flipped Classroom, la cual supone un rol activo del estudiante situándolo al centro del proceso educativo. Esto nos obligó a revisar las actuales prácticas pedagógicas y modelar un proceso de aprendizaje a distancia como eje central de la innovación, para posteriormente buscar las plataformas y herramientas tecnológicas que facilitaran la ideación.

A lo largo del documento, se repasan los principales aspectos que se trabajaron desde la ideación, justificación, modelo e implementación, y reflejar en resultados concretos lo que se ha logrado hasta el momento.

(cc) EY-NC-ND 2016, Universitat Politècnica de València 


\subsection{Objetivos}

\section{Objetivo General}

Desarrollar una modalidad semipresencial implementando una propuesta pedagógica adaptando la metodología Flipped Classroom en un Plan de Estudio de la Escuela de Informática y Telecomunicaciones de Duoc UC, con el fin de abordar estrategias de flexibilidad.

\section{Objetivos Específicos}

1. Identificar los Fundamentos Pedagógicos que sostienen la metodología Flipped para idear una modalidad semipresencial con elementos de flexibilidad, resguardando la alineación al Modelo Educativo Institucional.

2. Desarrollar un Modelo Pedagógico con características de Autoaprendizaje en los ambientes de aprendizaje, presencial y virtual, para generar aprendizaje activo, contextualizado y significativo en los estudiantes

3. Rediseñar los Procesos de Diseño y Producción Instruccional para dar cuenta de la ideación pedagógica a través de Objetos de Aprendizajes que integren todos los elementos definidos en el Modelo.

4. Implementar la modalidad semipresencial en las Carreras de Analista Programador Computacional y Administración de Redes Computacionales, considerando acciones de acompañamiento en este proceso de adopción, que estudiantes y docentes necesitan para la comprensión de sus roles en este modelo pedagógico.

5. Establecer mecanismos de seguimiento y control sobre esta implementación para controlar variables críticas del proceso y cumplir con la estrategia de mejora continua de la Institución.

\section{Desarrollo de la Innovación}

\subsection{Fundamentos Pedagógicos de la modalidad}

\subsubsection{Teorías del Aprendizaje}

El modelo educativo de la modalidad semipresencial Flipped Classroom, incluye varios elementos de las teorías de aprendizaje, haciendo una fusión de paradigmas como el conductismo, cognitivismo, constructivismo y el conectivismo, buscando perfilar una enseñanza-aprendizaje centrada en el estudiante. La finalidad de esta mixtura de corrientes, busca desarrollar ciertas conductas y acciones del estudiante en distintos momentos de su proceso formativo tanto en la parte presencial y no presencial; de ahí que estas instancias consideran en sus dinámicas un aprendizaje significativo donde el estudiante memorice, repita, reconozca, tome decisiones, resuelva, cree, construya y reflexione (Crome, Farrar, \& O’Connor, 2009).

Esta fusión de ideaciones sustenta a nuestra modalidad en distintas instancias de las experiencias de aprendizaje, considerando elementos pedagógicos que centran al estudiante y su proceso de aprendizaje como

pilar fundamental, articulando todos los elementos instruccionales y estrategias de enseñanza para lograr de manera exitosa el aprendizaje del estudiante.

(c)) EY-NC-ND 2016, Universitat Politècnica de València

Congreso In-Red (2016) 


\section{Teorías del Aprendizaje y su participación en la Modalidad Flipped Semipresencial}

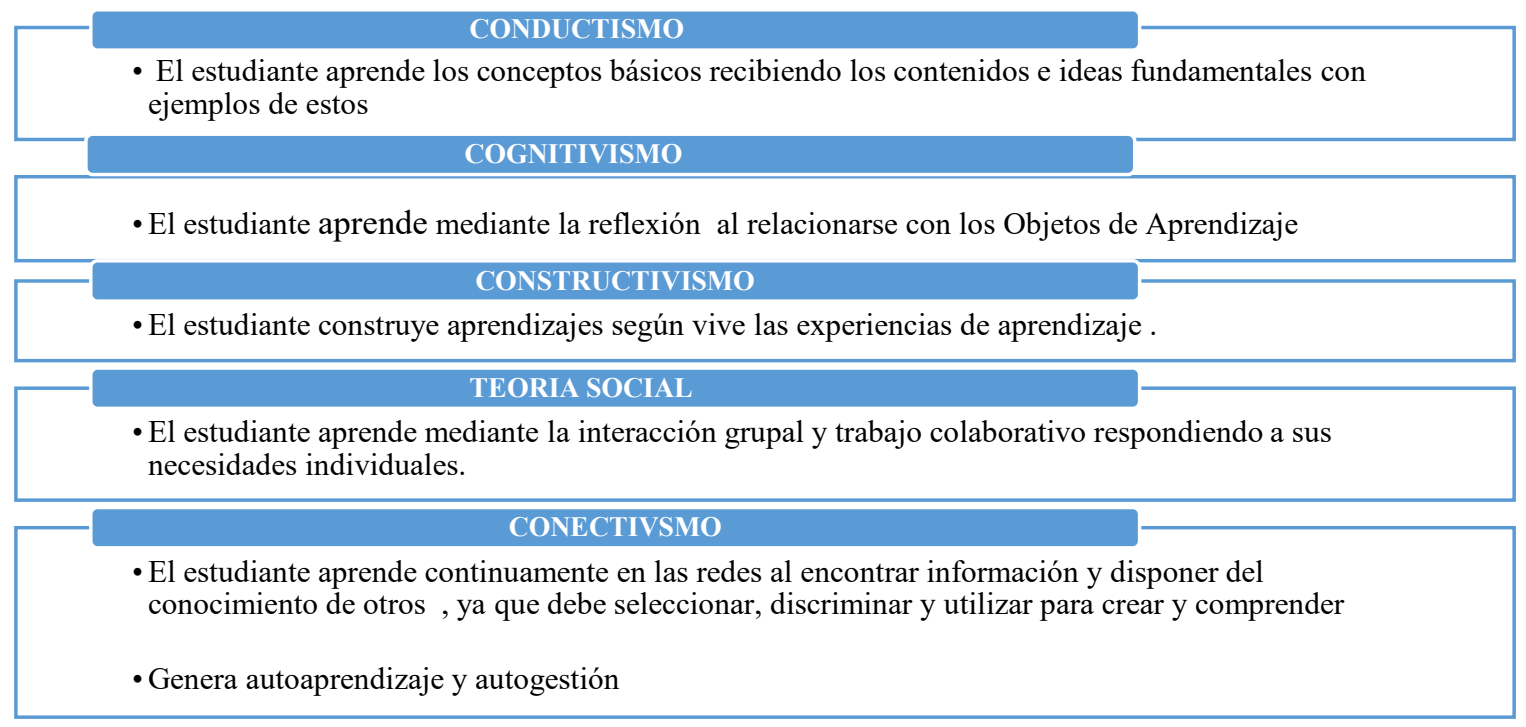

Tabla: Elaboración propia

Es así, que esta modalidad posibilita el aprendizaje activo del individuo, debido a que todos los componentes del diseño y producción instruccional se articulan buscando favorecer el aprendizaje significativo. Por ello, las secuencias didácticas, su estructura y objetos de aprendizaje en ambos ambientes de aprendizaje, virtual y presencial, son ideados en función de la interacción que éste establece en diferentes instancias de su formación, ordenadas intencionadamente con el fin de lograr la adquisición de aprendizajes y competencias (Álvarez Álvarez, González Mieres, \& García Rodríguez, 2007)

Todo lo anterior, guía a la modalidad para considerar:

- Estrategias que fomenten el aprendizaje por descubrimiento, cooperativo, colaborador y contextual.

- Las experiencias de aprendizaje deberán abordan los contenidos considerando su comprensión, construcción; y en la fase de cierre, la reflexión y retroalimentación; secuencia que complementa y refuerza las fases del proceso de enseñanza-aprendizaje.

- Las Estrategias deben ser congruentes y pertinentes con el contenido, los aprendizajes y las competencias que se pretende formar en los estudiantes.

\subsubsection{Tendencias y Conceptos}

Para la ideación de nuestra modalidad, además de considerar las teorías del aprendizaje, indagamos una serie de tendencias y conceptos asociados al aprendizaje autónomo, desarrollo de habilidades y la manera en la que se diseñan y disponen los recursos digitales a los estudiantes, entre otros, podemos mencionar como tendencias:

- MOOCs. Esta instancia busca ampliar el proceso de formación de las personas, centrándose en el aprendizaje social y abierto, utilizando actividades que generen conocimiento compartido e interacción en redes profesionales. Es decir, aprender con MOOCs se presenta como una oportunidad gratuita y social a través de la tecnología. (http://educalab.es/mooc).

(c)) EY-NC-ND 2016, Universitat Politècnica de València 
- Academia Khan. Ofrece ejercicios de práctica, videos instructivos y un panel de aprendizaje personalizado que permite a los alumnos aprender a su propio ritmo, dentro y fuera del salón de clases. (https://es.khanacademy.org/about).

- Code School. Es una página para aprender a programar en diferentes lenguajes. Puedes aprender mientras practicas lo que viste en la lección teórica, impartida en vídeos, las cuales puedes descargar. Lo entretenido de sus tutoriales es que combinan los screencasts, retos de código y el concepto de gamificación. Cabe destacar este último concepto, Gamificación, ya que cada curso te da medallas al finalizarlos y medallas al terminar las lecciones. Si bien no son un reconocimiento académico, es un incentivo para completar el curso y divertirse con los otros miembros de la comunidad (https://www.codeschool.com/).

- Open English. Los estudiantes tienen acceso a clases en vivo en salones virtuales, las 24 horas del día. De esta forma, pueden interactuar y conversar en inglés con mayor frecuencia, con la ventaja de tener un profesor orientándolo en la pronunciación y la gramática. (www.openenglish.com/).

- Stack overflow. Es un sitio de preguntas y respuestas para programadores y profesionales de la informática. Cualquiera puede formular una pregunta. Cualquiera puede responder. Se vota a favor de las mejores respuestas, y estas suben a los primeros puestos (http://www.stackoverflow.com/).

También podemos mencionar como conceptos, los siguientes:

- Aprendizaje Activo

- Engagement

- Gamificación

- Aprendizaje experiencial

- Aprendizaje Basado en Problemas

- Autoaprendizaje

\section{Desarrollo modelo con características de Autoaprendizaje}

La implementación de la metodología Flipped significó el desarrollo de un modelo pedagógico con características de Autoaprendizaje que posibilite eficazmente los aprendizajes en las horas no presenciales de la modalidad, modelo soportado a través de 3 pilares fundamentales: Contenido Enriquecido, Plataforma de Simulación o experimentación (ejercitación) y Auto-Assessment (retroalimentación). El Contenido Enriquecido se refiere a los objetos de Aprendizaje que cuentan con fuerte apoyo audiovisual, elaborados a partir de guiones que enfatizan la significancia y contextualización de los conceptos que se pretenden entregar.

\subsection{Modelo Pedagógico}

La propuesta de Flipped Classroom propone que en clase se realicen actividades tipo taller con los estudiantes y que los aspectos teóricos de las asignaturas se revisen en casa. Esta manera de enseñar hace necesario que la oralidad del discurso docente, se transforme en recursos de contenido y objetos de aprendizaje para que el estudiante pueda acceder por distintos medios y recursos audiovisuales. Aquello tiene mucho sentido, ya que en clases se aprovecha la presencia de los compañeros y del profesor, generando actividades que potencian y activan el aprendizaje colaborativo (http://www.theflippedclassroom.es/)

\subsection{Diseño Instruccional}

En una modalidad con estas características, el diseño instruccional requiere de sobre manera ser un proceso planificado y estructurado, el cual genera el $t$ de recursos educativos de gran variedad los cuales buscan asegurar de la calidad del aprendizaje de los estudiantes. Además se asume una estrecha relación entre la implementación de las tecnologías.

\subsubsection{Experiencia de Aprendizaje (EA)}

Nuestras experiencias de aprendizaje, expresan una fusión de los paradigmas educativos a lo largo de su estructura. Para ello, se idean materiales que busquen la memorización, clasificación, asimilación de conductas, asociación, razonamiento, análisis, solución de problemas y utilización de los aprendizajes entre otros. Además, todas las EA se crean considerando el nivel de complejidad de sus aprendizajes 
esperados y su respectiva Unidad de Aprendizaje. Tanto los objetos de aprendizaje que forman la parte no presencial como la parte presencial, tienen una funcionalidad que hace a esta estructura, la expresión del fin del logro de los aprendizajes por el estudiante.

Por otra parte, se incorporan las llamadas habilidades del $s$ XXI a la ideación y diseño de los objetos de aprendizaje. Entre ellas podemos mencionar Tolerancia a la Frustración; Trabajo en Equipo y Trabajo bajo presión entre otras.

Todo lo anterior, se plasma en el Mapa Instruccional, Hoja de ruta, Actividades, Evaluaciones entre otros; los cuales conforman el Plan Didáctico de Aula (PDA), plantillas que dan vida a las experiencias de aprendizaje en su ideación, ya que expresan la relación de los aprendizajes esperados con todos los recursos mencionados.

- Mapa Instruccional: Es un documento que permite el entendimiento común y de consenso del diseño de los recursos de la asignatura. Expresa ideación pedagógica, orden e intencionalidad de los OA.

- Patrones de diseño: Constantes en la estructura de los OA, son ciertas características base que deben orientar la creación y diseño de estos recursos.

\subsubsection{Objetos de Aprendizaje (OA)}

La existencia de objetos de aprendizaje en nuestra modalidad, es la evidencia de que el contenido ya no es el centro del diseño pasando a ser sólo un medio para el logro del aprendizaje de determinadas temáticas.

Es así que los $\mathrm{OA}$ se conciben como elementos integrados e integradores del proceso de enseñanzaaprendizaje, ofreciendo a los estudiantes la posibilidad de mejorar su comprensión, rendimiento y nivel de satisfacción en su proceso formativo (Organización Internacional del Trabajo, OIT/Cinterfor, 2013).

A continuación mencionamos algunas características que guiaron su elaboración:

- Propósito pedagógico: el objetivo es asegurar un proceso de aprendizaje satisfactorio. Por tanto, el OA incluye no sólo los contenidos sino que también guía el propio proceso de aprendizaje del estudiante.

- Contenido enriquecido: Es necesario que el objeto incluya actividades (ejercicios, simulaciones, cuestionarios, diagramas, gráficos, diapositivas, tablas, exámenes, experimentos, etc.) que permitan facilitar el proceso de asimilación y el seguimiento del progreso de cada estudiante.

- Es Indivisible e independiente de otros objetos de aprendizaje

- Formato digital: tiene capacidad de actualización y/o modificación (IDEM).

\subsubsection{Evaluación de Aprendizajes: Assessment}

En esta modalidad la Evaluación para el Aprendizaje se presenta como una mirada constructiva del proceso educativo. Desde esa mirada, la Evaluación para el aprendizaje que consideramos contempla los siguientes elementos:

- Es parte de la planificación de las actividades

- Se centra en cómo aprenden los estudiantes

- Es central en las actividades presenciales y no presenciales

- Es un elemento que debe considerar profesional docente clave

- Retroalimenta a los estudiantes respecto a su nivel de logro

- Incide en la motivación del estudiante porque este conoce su avance

- Promueve un compromiso con las metas de aprendizaje y con criterios de evaluación

- Estimula el auto assessment

\section{Producción Instruccional}


El esquema pretende entregar una vista panorámica de un proceso que se ha dividido en 2 períodos académicos previos a la implementación en sede con los estudiantes. Lo anterior ,cumple dos propósitos, por una parte lograr instalar discusiones enfocadas en la modelación de procesos de aprendizaje que con tiempos adecuados de maduración permiten la reflexión necesaria para matizar los objetivos disciplinarios con la integración de habilidades y a su vez alineándose a las metodologías y patrones de diseño que la Escuela ha decidido implementar; y como segundo propósito, contar con las holguras de tiempo que minimicen los riesgos del proyecto, sobretodo en cuanto a la calidad de los productos que emanen del proceso, es usual en proyectos de cualquier índole que ante la falta de tiempo o falta de recursos se sacrifica calidad.

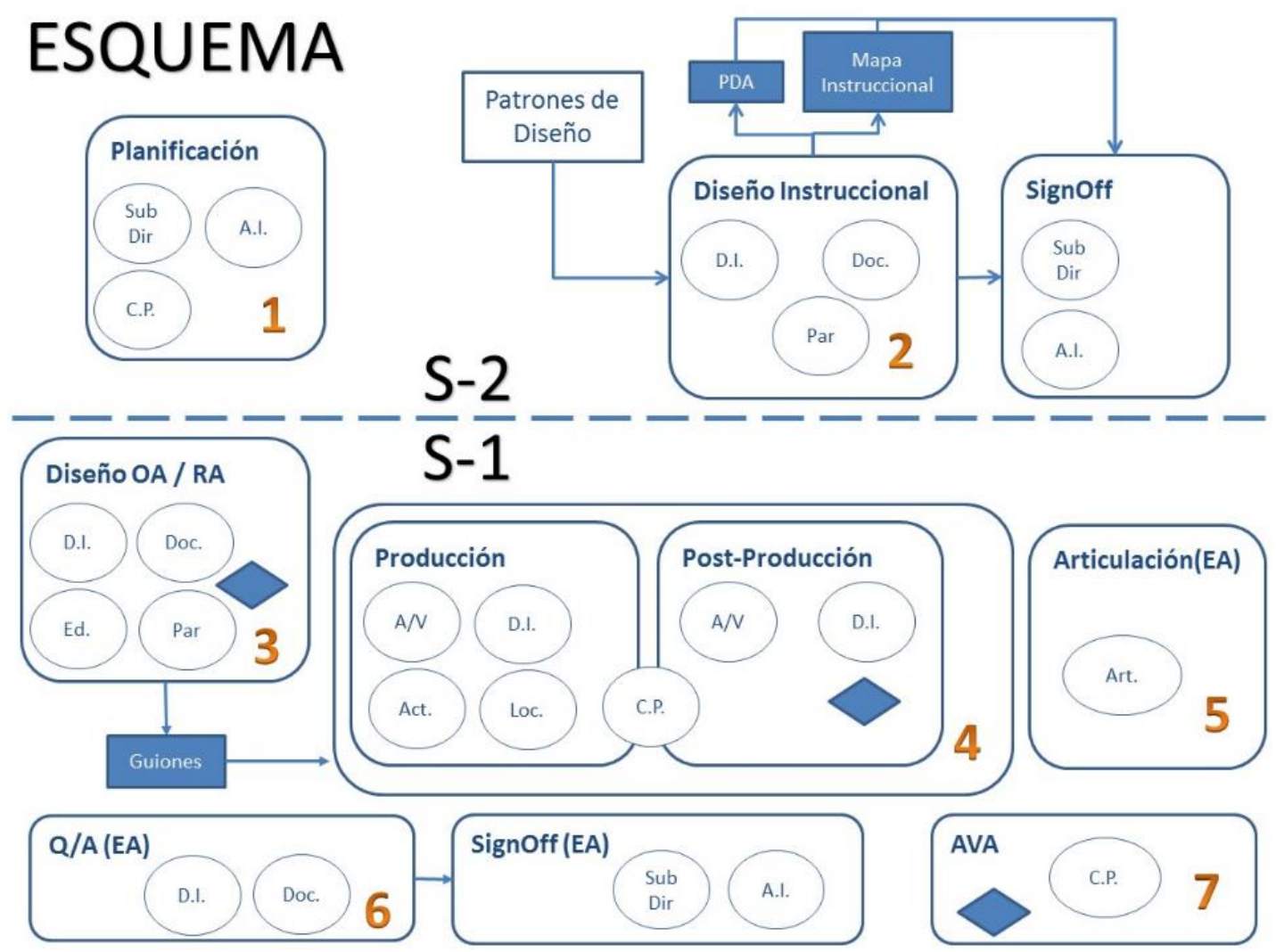

Símbolo: El rombo color azul señala la existencia de una instancia de validación constante sujeto a las acciones de seguimiento y control de avance.

El primer periodo de producción instruccional, denominado S-2, se debe llevar a cabo a lo menos 2 semestres antes del uso por parte de los alumnos, en la cual se llevan a cabo las siguientes etapas: 1) PLANIFICACIÓN; 2) DISEÑO.

La segunda parte, denominada S-1, se debe llevar a cabo a lo menos 1 semestre antes del uso por parte de los alumnos, cuenta con las siguientes etapas: 3) DISEÑO RA/OA; 4) PRODUCCIÓN / POST-PRODUCCIÓN; 5) ARTICULACIÓN; 6) Q/A; 7) AVA

\subsection{Roles en diseño y producción instruccional}

Dada la naturaleza de los elementos que se producen, es normal suponer la aparición de nuevos roles, sin embargo, es muy importante poner especial atención al rol de Diseñador Instruccional, pues representa un

(c)) EY-NC-ND 2016, Universitat Politècnica de València

Congreso In-Red (2016) 
cambio paradigmático en cuanto a la producción instruccional de una Escuela en Duoc UC. Tradicionalmente, una Escuela le otorga a un Docente un rol protagónico frente a un encargo instruccional, quien se lleva el encargo y lo entrega da acuerdo al plazo que se le coloca, aquí ese rol lo toma el Diseñador Instruccional, transformándose en el dueño o demandante del producto. A continuación se presentan algunos de los actores claves:

- Subdirector de Área

- Analista Instruccional

- Diseñador Instruccional

- Articulador

- Docente Desarrollador Instruccional

- Docente Experto en Contenidos (Par)

\section{Implementación modalidad semipresencial}

\subsection{Roles}

La operación de un producto educativo, en general, y de una modalidad flexible, en lo particular, reviste de una complejidad que requiere de la orquestación eficiente de distintos actores de diversas unidades de la Institución.

A saber los distintos roles provienen de las siguientes unidades institucionales:

- Vicerrectoría Académica (VRA)

- Dirección de Desarrollo Académico

- Dirección de Docencia

- Centro de Formación Docente - CFD

- Unidad de Apoyo Pedagógico - UAP

- Sedes

- Dirección de Sede

- Subdirector Académico

- Director de Carreras

○ Tutor

- Docentes

○ Estudiantes

○ Escuela

- Director de Escuela

- Subdirector de Área

- Analistas Instruccional/Curricular

- Diseñador Instruccional

○ Analista de Aseguramiento de la Calidad

Los marcados en negrita son roles fundamentales dentro del proceso en el momento de implementación en alguna sede de dicha modalidad.

\section{Condiciones de Ejecución}

Para una correcta ejecución del modelo, se debe tener previsto una serie de acciones que tienen el propósito de mitigar los riegos de falla que puedan debilitar o anular la experiencia de aprendizaje de los alumnos. Se 
espera que se puedan concentrar en 3 grandes ámbitos, las acciones de Habilitación de Estudiantes, el Soporte Pedagógico y el Soporte Tecnológico.

- Habilitación estudiantes Es muy importante precisar que este punto sólo se refiere a la habilitación de los estudiantes en la modalidad semipresencial desde los conceptos más básicos e introductorios a la metodología que han suscrito los alumnos al ingresar a la carrera, así como asegurar un conocimiento en el uso de los sistemas y plataformas de Duoc UC. Sin embargo, desde el punto de vista de la habilitación del estudiante en el modelo, esta adopción requiere de un soporte pedagógico enfocado constante por parte del tutor. Bajo esta instancia cabe la Firma de Protocolo y Socialización Inicial mencionadas anteriormente.

- Soporte Pedagógico. El aspecto primordial de la modalidad es todo lo referente a la pedagogía que soporta este modelo y lo diferencia de otros como valor agregado. Vale entonces resguardar la pedagogía con el soporte que sea necesario para que se pueda asegurar un funcionamiento acorde con el diseño instruccional y fundamentos pedagógicos de la Escuela. A continuación se mencionan algunas de las líneas de acción que a lo menos debiera suceder en Sede.

- Coordinación de Línea. Las asignaturas que cuentan con Coordinación de Línea centralizada en Escuela, sus secciones en modalidad semipresencial, también pasan bajo el control de este estamento de Escuela. Es decir, que se alienan al cronograma, a la supervisión de las instancias evaluativas sumativas y auditoría aplicación ET, y asistir a las reuniones en Sede con el Coordinador de Línea.

- Aseguramiento de la Calidad. Parte del soporte pedagógico se sostiene en el cumplimiento de aspectos formales del modelo, como seguimiento de la aplicación de la maleta didáctica, verificación de la habilitación docente se haya realizado de acuerdo a los lineamientos de Escuela, realización de partes presenciales en talleres o laboratorios que cuenten con los estándares de Escuela específicos. Verificación de la cantidad de alumnos por sección de acuerdo a los estándares de Escuela. Verificación de la Programación Académica de acuerdo a los criterios de horario para la modalidad semipresencial. Verificación de la aplicación de los procesos de definidos por la Escuela. Da seguimiento al plan de mejoras de la carrera en la Sede. Además se realiza una visita a la Sede para verificar esto y otros antecedentes con el Director de Carreras, instancia de la cual se elabora una Informe que se envía a la Dirección de Sede posterior a la aceptación de éste por parte del Director de Carreras.

- UAP (Unidad de Apoyo Pedagógico). En su rol de soporte pedagógico constante, se espera acompañe a los docentes en sus desafíos de impartir docencia en esta modalidad que utiliza metodologías activas de aprendizaje y tecnología educativa para responder al modelo. La observación en Aula debe ser realizada de manera efectiva y enfocada en entregar a una retroalimentación en la aplicación de las metodologías señaladas.

○ Tutor: Alumnos - Docentes

- Monitoreo actividad: No Presencial y Presencial

- Atención de alumnos

- Supervisión Docente

○ Soporte Tecnológico. A cargo de:

- Enrolamientos

- Conectividad

(c) EY-NC-ND 2016, Universitat Politècnica de València

Congreso In-Red (2016) 
- Cetecom (Pañolero). Para asegurar la continuidad operacional de los laboratorios de especialidad de los alumnos y en los tiempos específicos en que el estudiante semipresencial se encuentra en Sede. Lo anterior obliga a mantener una estrecha colaboración y coordinación entre Cetecom y el equipo de Dirección de Carrera, de tal forma de establecer mecanismos de mejora continua en conjunto, específicamente en estos temas de soporte.

\section{Mecanismos de seguimiento y control 6.1. Procesos de mejora continua}

Para facilitar la evolución del modelo y la optimización de los indicadores académicos que rinden cuenta del éxito del producto, se debe llevar a cabo todas las acciones que están previstas bajo la estrategia de mejora continua definida por la Escuela. Estas acciones cuentan con la coordinación y control del Analista de Aseguramiento de Calidad de la Escuela.

- Retroalimentación levantada en Sede. Se deben presupuestar, planificar y diseñar el levantamiento de información específica a través de sesiones Focus Group con alumnos, así como entrevistas individualizadas con diversos actores que intervienen en los procesos de aprendizaje de los alumnos, docentes o coordinadores. De esta forma se espera obtener indicadores e información valiosa y estructurada que se pueda poner al servicio del Área Instruccional como insumo para futuros Rediseños.

- Reuniones Equipo Escuela. Resulta conveniente planificar un calendario de reuniones donde sesione el equipo escuela suscritos a la Modalidad. Los convocados a esta instancia son los Subdirectores de Área, Directores de Carreras y Tutores. Dependiendo de la tabla en pauta es que se puede citar adicionalmente al Diseñador Instruccional, Analista Instruccional. Las personas que asisten regularmente a esta instancia conforman el Comité de Operación de la Modalidad.

\subsection{Control de gestión académica en sede}

\section{- Seguimiento a Operación Modalidad / indicadores académicos}

Es muy importante que todo el equipo de la sede realice un seguimiento constante a la operación de esta modalidad así como se hace con las otras modalidades, esto quiere decir que SDA, DC, tutores y docentes deben conocer inasistencia de los alumnos, rendimiento académico, tiempo de conexión a la plataforma (dedicación a la modalidad), etc. Inclusión de la modalidad en los procesos Escuela: al igual que otras modalidades, ésta debe insertarse en los distintos procesos de Escuela durante su ejecución, esto incluye que los docentes deben enviar sus pruebas para revisión a los coordinadores de línea, deben asistir a las reuniones de línea, deben entregar a los DC toda la evidencia e informes que estos soliciten, deben aplicar en sus asignaturas los mismos ET que en otras modalidades, ya que las mismas asignaturas buscan alcanzar las mismas competencias.

\section{- Reuniones Equipo Sede}

Se deben realizar reuniones quincenales o mensuales (dependerá del nivel de madurez de la Sede respecto de la modalidad) de seguimiento a los informes que prepara el tutor. A esta reunión convoca al Director de Carreras, Coordinador Vespertino, Tutor, Docentes, UAP, Cetecom. En ocasiones, y dependiendo de la Tabla en pauta se puede invitar al Analista Instruccional, Subdirector de Área o Subdirector Académico de la Sede. A esta instancia se le puede denominar Comité de Operación Sede. 


\section{Resultados}

\subsection{Vistas finales de los objetos de aprendizaje y entorno virtual}

A continuación se presentan el formato de los recursos que integran un Objeto de Aprendizaje. Cabe señalar que estas secuencias didácticas se empaquetan a un formato SCORM.

Cápsula de Introducción:

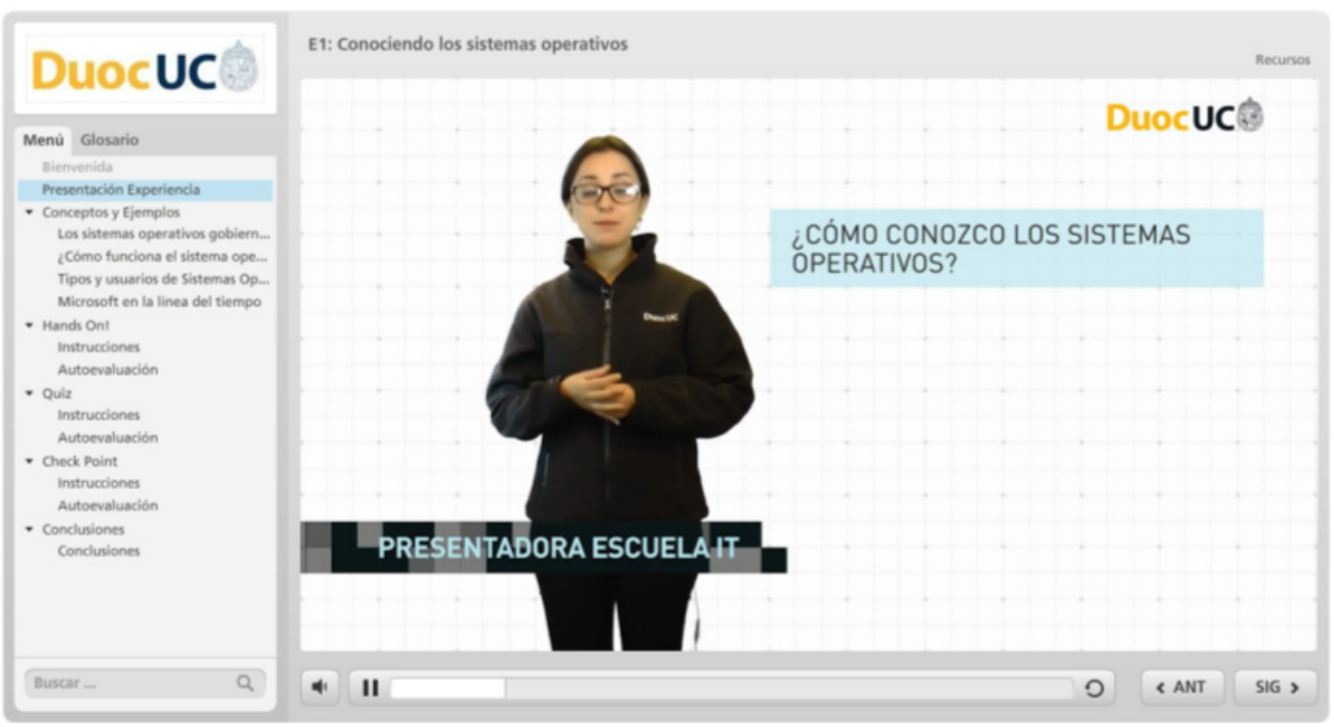

(c) EY-NC-ND 2016, Universitat Politècnica de València 
Cápsulas de Conceptos y Ejemplos
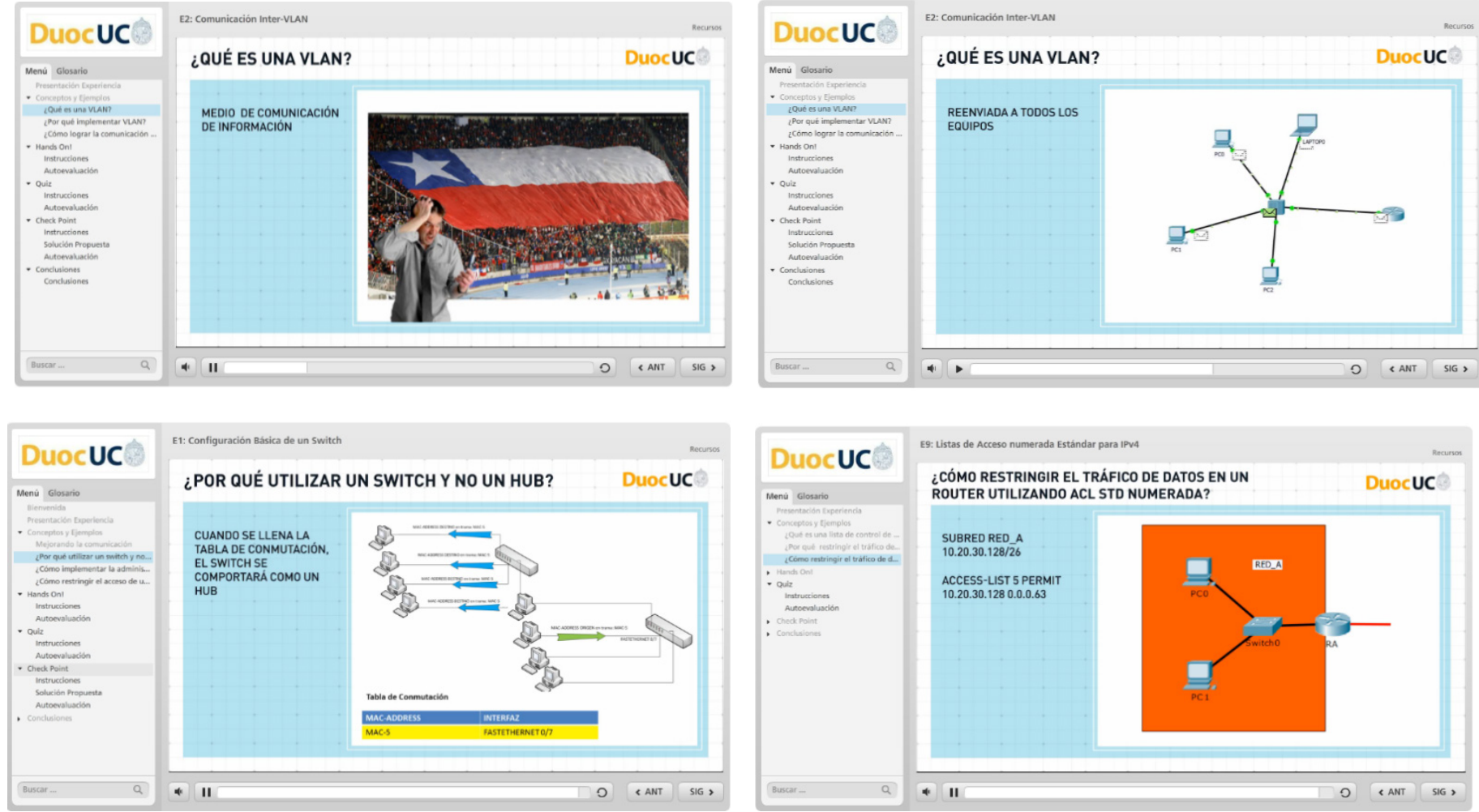

Vista del curso en el Ambiente Virtual de Aprendizaje Blackboard.

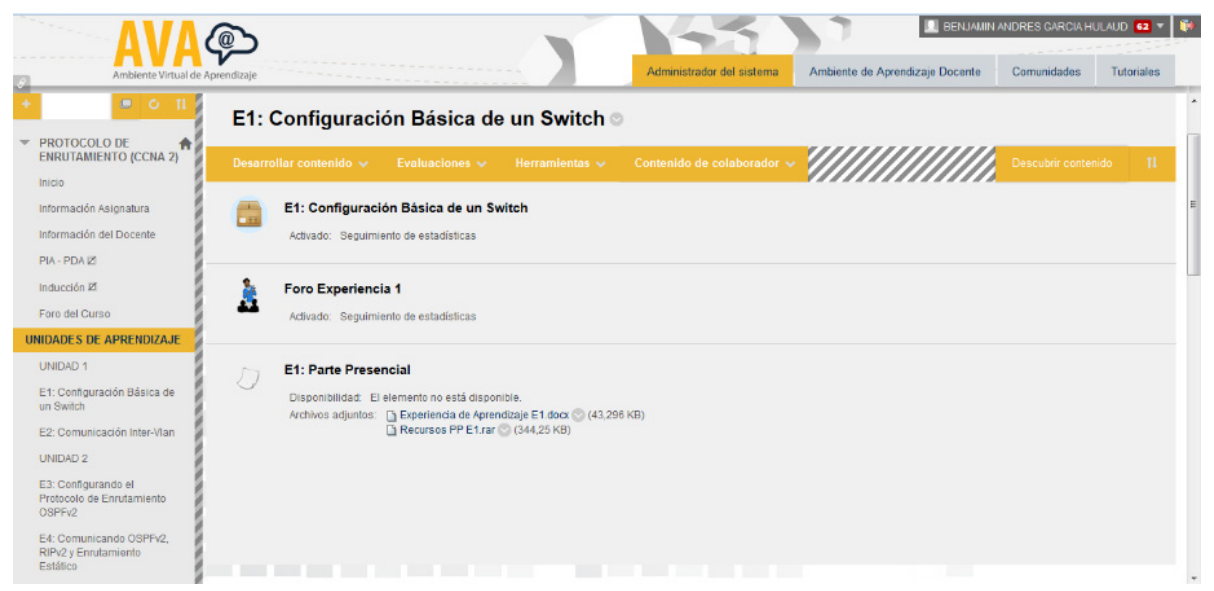

(cc) EY-NC-ND 2016, Universitat Politècnica de València 
Entorno de Simulación

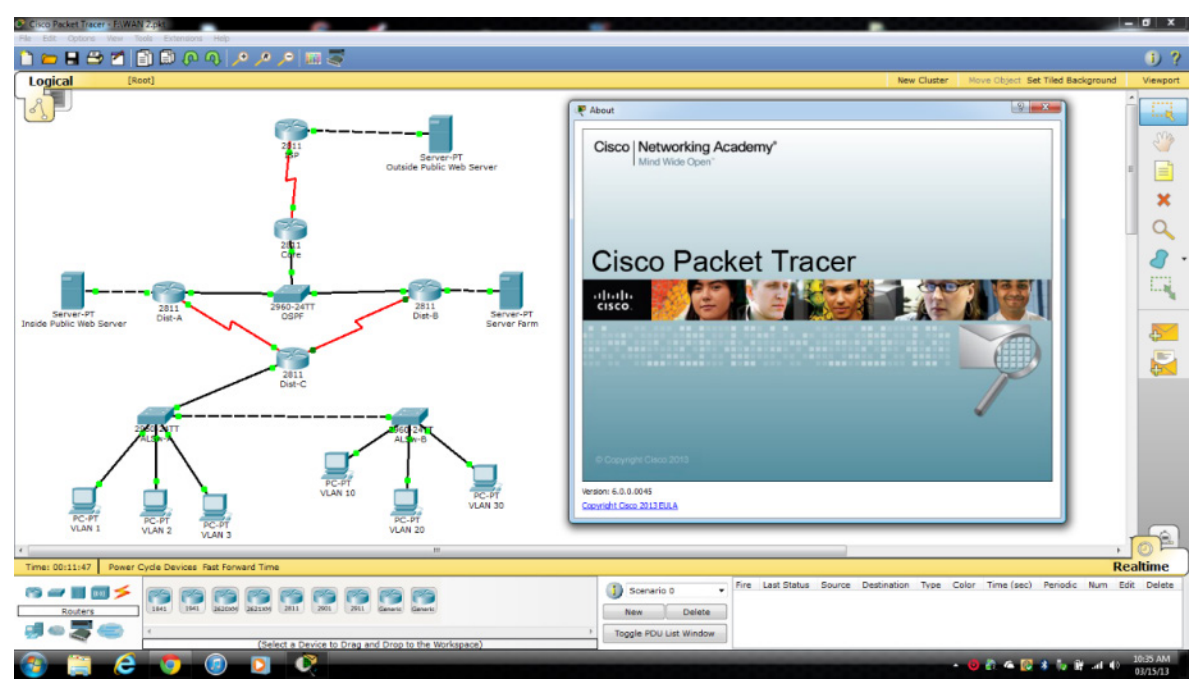

Assessment y Auto Evaluaciones:

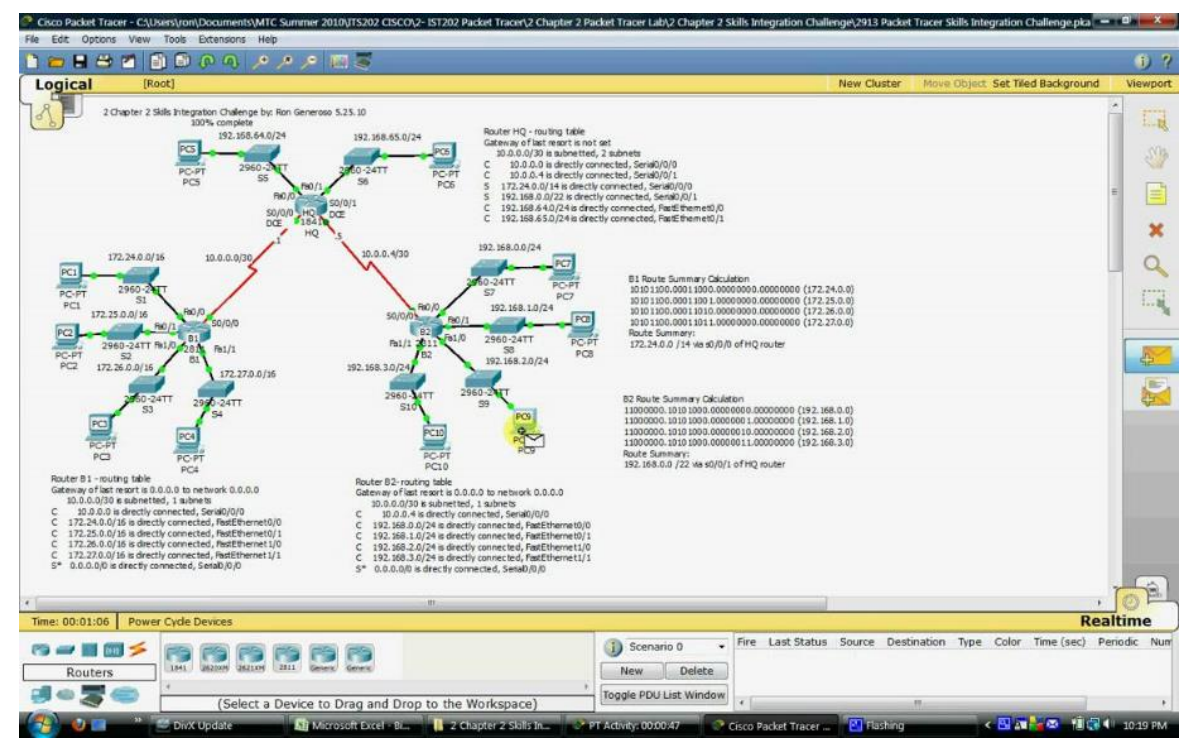

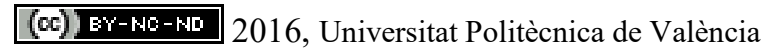

Congreso In-Red (2016) 
Video Solución Tarea CheckPoint:

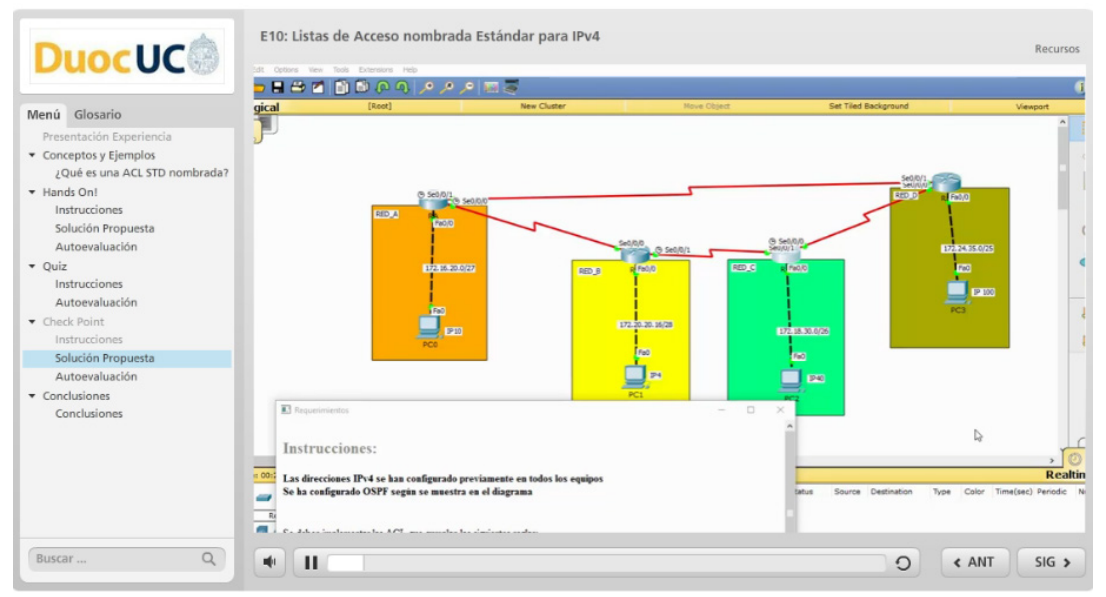

Autoevaluación a la tarea realizada:

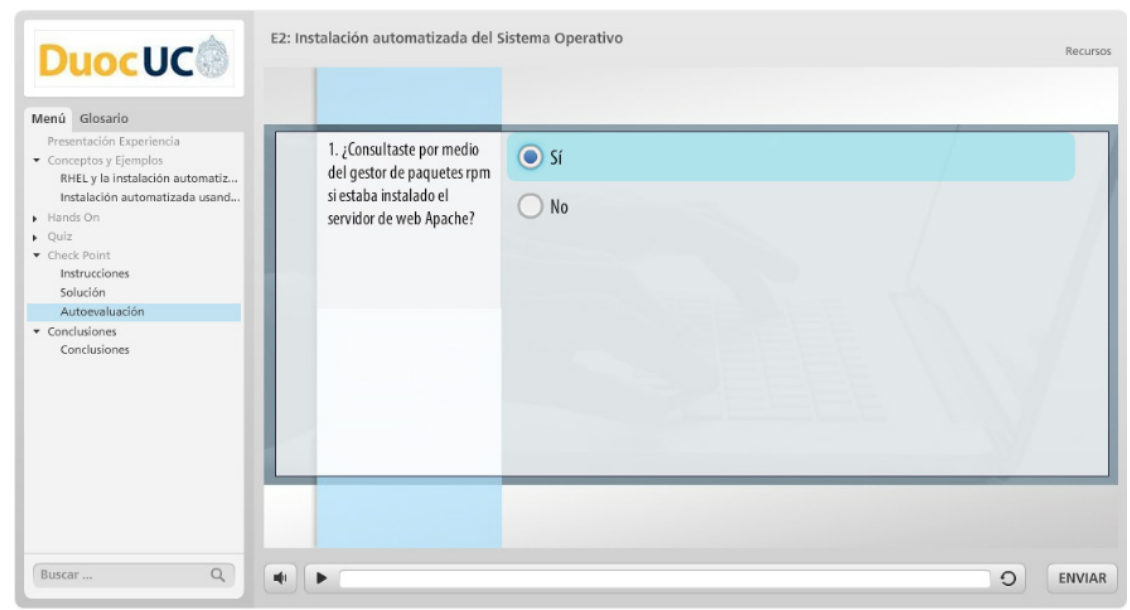

Retroalimentación desde el mismo simulador:

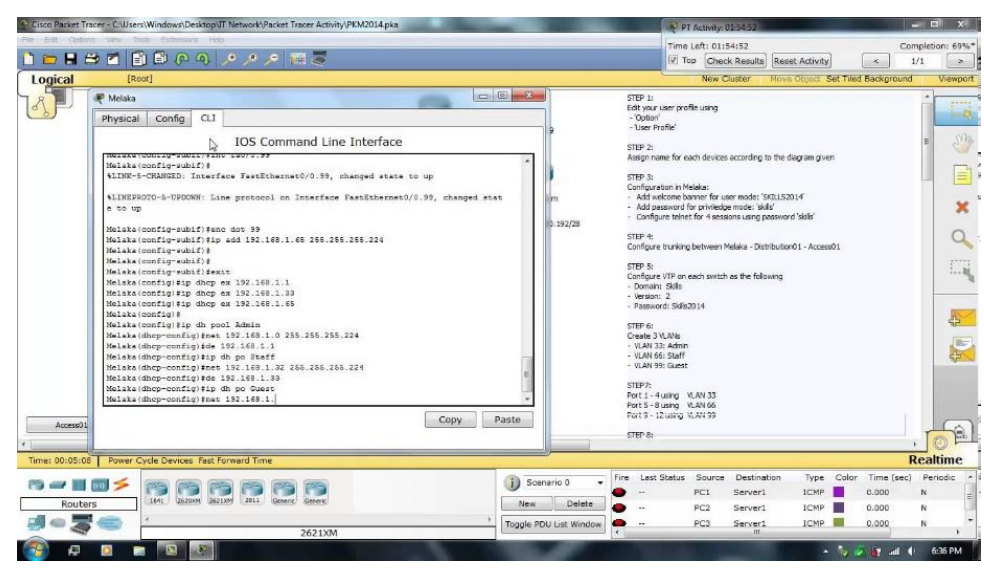

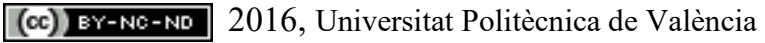



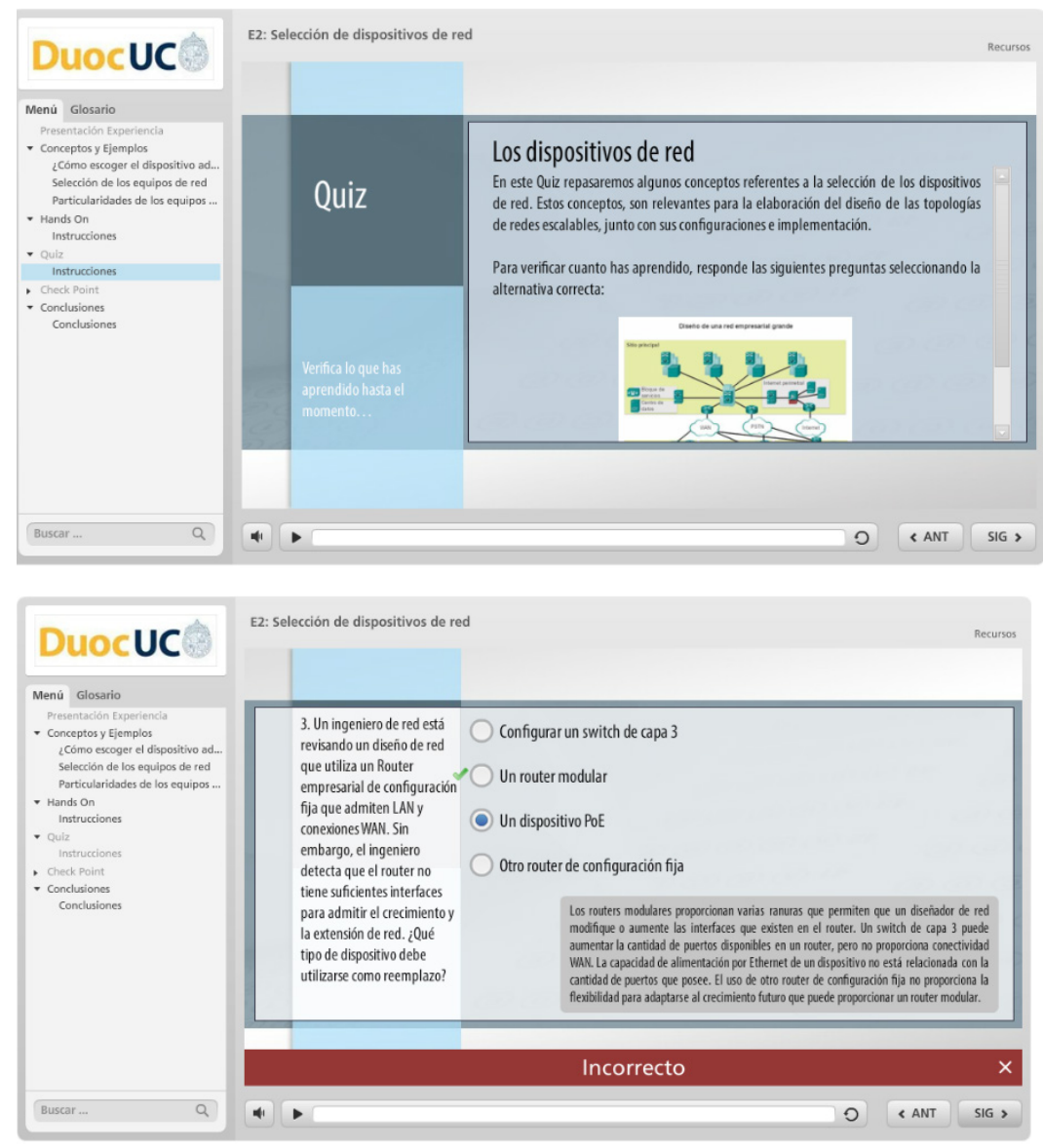

\subsection{Resultados Académicos comparados con modalidad tradicional}

A modo de contexto, es importante mostrar algunos datos asociados a los Planes de Estudios y las respectivas Sedes de Duoc UC donde se imparten en modalidad semipresencial Flipped Classroom (SPFC). El primer plan de estudios en ser adaptado fue la carrera técnica de 5 semestres, Analista Programador Computacional (APC), en la Sede San Joaquín de Duoc UC, abriendo 30 matrículas de inicio en jornada vespertina para el primer semestre del año 2014. Al año siguiente, junto con la respectiva continuidad de los alumnos de San Joaquín (es decir matrículas de inicio y continuidad), otras dos sedes deciden adoptar la modalidad SPFC, la Sede Melipilla con 17 matrículas de inicio y Sede Plaza Oeste con 29 matrículas de inicio, ambas en jornada vespertina. Ese mismo año 2015, se adapta a modalidad SPFC la carrera técnica de 5 semestres, Administración de Redes Computacionales (ARC), abriendo 30 matrículas de inicio en jornada vespertina. 


\begin{tabular}{|c|l|c|c|c|c|c|c|}
\cline { 3 - 9 } \multicolumn{2}{c|}{} & \multicolumn{2}{c|}{$\mathbf{2 0 1 4}$} & \multicolumn{2}{c|}{$\mathbf{2 0 1 5}$} & \multicolumn{2}{c|}{$\mathbf{2 0 1 6}$} \\
\hline Carrera & Sede & Matrícula & Docentes & Matrícula & Docentes & Matrícula & Docentes \\
\hline APC & San Joaquín & 30 & 5 & 49 & 6 & 73 & 7 \\
\hline APC & Plaza Oeste & 0 & 0 & 29 & 3 & 69 & 6 \\
\hline APC & Melipilla & 0 & 0 & 17 & 4 & 36 & 5 \\
\hline ARC & Viña del Mar & 0 & 0 & 30 & 6 & 40 & 6 \\
\hline
\end{tabular}

\begin{tabular}{|r|c|c|c|}
\cline { 2 - 4 } \multicolumn{1}{c|}{} & \multicolumn{3}{c|}{ Cantidad de Asignaturas en SPFC } \\
\hline Carrera & $\mathbf{2 0 1 4}$ & $\mathbf{2 0 1 5}$ & 1er Sem. 2016 \\
\hline APC & 6 & 13 & 15 \\
\hline ARC & 0 & 6 & 10 \\
\hline Total en SPFC & $\mathbf{6}$ & $\mathbf{1 9}$ & $\mathbf{2 5}$ \\
\hline Total Docentes SPFC & $\mathbf{5}$ & $\mathbf{1 9}$ & $\mathbf{2 4}$ \\
\hline
\end{tabular}

A continuación, se revisarán los datos de aprobación de los exámenes transversales (ET) y aprobación final de las asignaturas SPFC comparadas con sus respectivas versiones tradicionales en mismo periodo académico. Es importante señalar, que los exámenes transversales son elaborados bajo un proceso controlado de diseño central, el cual es observado por pares evaluadores y liberados a sedes para ser aplicados a todas las secciones de la asignatura, en todas las sedes y en todas las modalidades. Bajo este mecanismo se pueden tomar acciones de seguimiento y control de la homogeneidad del proceso de enseñanza/aprendizaje, ya que independiente de todas las condiciones de borde, el perfil de egreso es el mismo. Primero, se mostrarán datos resumidos del desempeño académico 2015 y la deserción del mismo año. Luego, se mostrarán los resultados de cada periodo académico por separado del 2015. La sigla PEV significa Programa Ejecutivo Vespertino, y es una nomenclatura institucional para clasificar planes de estudio semipresenciales.

\begin{tabular}{|c|c|c|c|c|}
\hline & AÑO 20 & \multicolumn{3}{|c|}{ Aprobación Promedio } \\
\hline Carrera & Modalidad & \multicolumn{2}{|c|}{ E.T. } & Final \\
\hline \multirow{2}{*}{ APC } & \multicolumn{2}{|c|}{ Semipresencial } & $70 \%$ & $72 \%$ \\
\hline & Presencial & \multicolumn{2}{|c|}{$75 \%$} & $71 \%$ \\
\hline \multirow{2}{*}{ ARC } & Semipresencial & \multicolumn{2}{|c|}{$85 \%$} & $85 \%$ \\
\hline & Presencial & \multicolumn{2}{|c|}{$86 \%$} & $78 \%$ \\
\hline \multicolumn{2}{|c|}{ AÑO 2015} & \multicolumn{3}{|c|}{ Aprobación Promedio } \\
\hline \multicolumn{2}{|c|}{ Modalidad } & \multicolumn{2}{|c|}{ E.T. } & Final \\
\hline \multicolumn{2}{|c|}{ Semipresencial } & \multicolumn{2}{|l|}{$74 \%$} & $76 \%$ \\
\hline \multicolumn{2}{|c|}{ Presencial } & $78 \%$ & & $73 \%$ \\
\hline & \multicolumn{2}{|c|}{ AÑO 2015} & \multicolumn{2}{|c|}{ Deserción } \\
\hline Carrera & Modalida & & Inicio & Continuidad \\
\hline \multirow{2}{*}{ APC } & \multicolumn{2}{|c|}{ SemiPresencial } & $32.89 \%$ & $36.84 \% *$ \\
\hline & \multicolumn{2}{|c|}{ Presencial (Vesp.) } & $32.40 \%$ & $19.69 \%$ \\
\hline \multirow{3}{*}{ ARC } & \multicolumn{2}{|c|}{ SemiPresencial } & $36.67 \%$ & - \\
\hline & \multicolumn{2}{|c|}{ Presencial (Vesp.) } & $33.68 \%$ & - \\
\hline & & & * Sólo 1 Sede & San Joaquín) \\
\hline
\end{tabular}

(c) EY-NC-ND 2016, Universitat Politècnica de València 


\section{Rendimiento de Asignatura 2015-2}

\section{Analista Programador Computacional PEV}

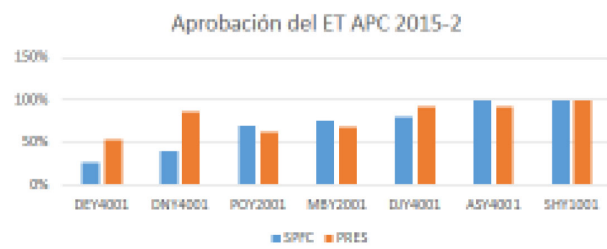

\begin{tabular}{|c|c|c|c|c|c|c|c|}
\hline Asignaturn & Moo & $\begin{array}{c}x \\
\text { Aprobado } \\
\text { s Examen }\end{array}$ & $\begin{array}{l}\text { Prom. } \\
\text { Nota } \\
\text { Examen }\end{array}$ & $\begin{array}{c}n^{\circ} \\
\text { Alumnes } \\
\text { inserites }\end{array}$ & $\begin{array}{l}n^{*} \\
\text { slummoz } \\
\text { rindieron } \\
\text { LT }\end{array}$ & $\begin{array}{l}\text { X de } \\
\text { retensican }\end{array}$ & $\begin{array}{c}\text { Aprobsila } \\
= \\
\text { Final }\end{array}$ \\
\hline \multirow{2}{*}{$A S Y 4001$} & SFFC & $100 \%$ & 5,6 & 13 & 11 & $85 \%$ & $85 \%$ \\
\hline & PRES & $93 \%$ & 5,3 & 322 & 253 & $75 \%$ & $76 \%$ \\
\hline \multirow{2}{*}{ DEY4001 } & SPFC & $27 \%$ & 39 & 15 & 11 & $73 \%$ & $73 \%$ \\
\hline & PRES & $53 \%$ & 4,3 & 364 & 284 & $77 \%$ & $66 \%$ \\
\hline \multirow{2}{*}{ D. .54001} & SFFC & $80 \%$ & 4,5 & 11 & 10 & $91 \%$ & 91\% \\
\hline & PRES & $02 \%$ & 5,4 & 306 & 200 & $68 \%$ & $64 \%$ \\
\hline \multirow{2}{*}{ DWY4001 } & SPFC & $40 \%$ & 4,0 & 10 & 10 & $100 \%$ & $100 \%$ \\
\hline & PRES & $86 \%$ & 4,9 & 301 & 247 & $82 \%$ & $78 \%$ \\
\hline \multirow{2}{*}{ MEY2001 } & SPFC & $78 \%$ & 4,7 & 61 & 46 & $76 \%$ & $72 \%$ \\
\hline & PRES & $60 \%$ & 46 & 395 & 283 & $74 \%$ & $75 \%$ \\
\hline \multirow{2}{*}{ Por2001 } & SFFC & $70 \%$ & 4,4 & 53 & 43 & $811 \%$ & 689 \\
\hline & PRES & $63 \%$ & 4,6 & 367 & 304 & $93 \%$ & $70 \%$ \\
\hline \multirow{2}{*}{ SHY1001 } & SPFC & $100 \%$ & 6,6 & 56 & 48 & $86 \%$ & $66 \%$ \\
\hline & PRES & $96 \%$ & 6,4 & 337 & 300 & $89 \%$ & $89 \%$ \\
\hline
\end{tabular}

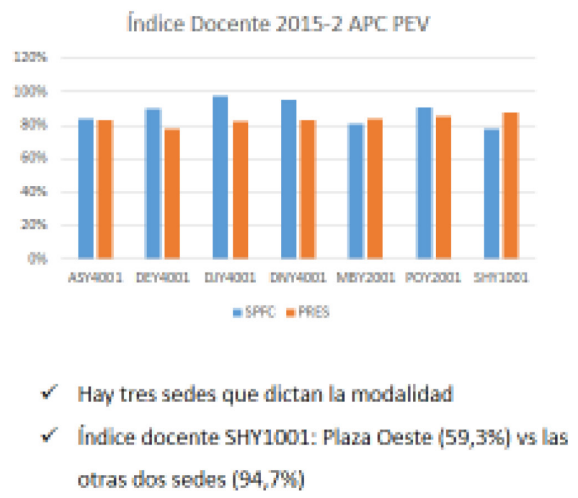

$\checkmark$ Indice docente SHY1001: Plaza Ceste $(59,3 \%)$ ws las otras dos sedes $(94,7 \%)$

\section{Rendimiento de Asignatura 2015-2}

Administración de Redes Computacionales PEV

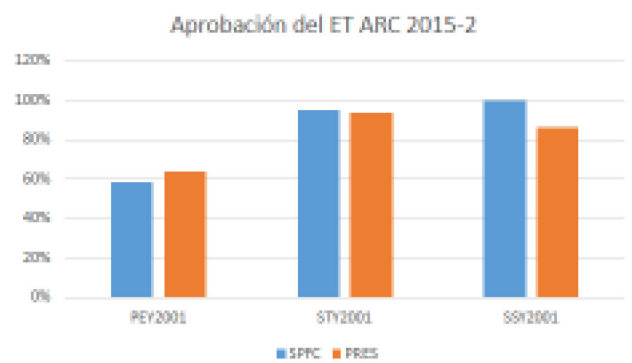

\begin{tabular}{|c|c|c|c|c|c|c|c|}
\hline Aclanotura & MoD & $\begin{array}{c}\% \\
\text { Aprobados } \\
\text { Examen }\end{array}$ & $\begin{array}{l}\text { Prom. } \\
\text { Nota } \\
\text { Examen }\end{array}$ & $\begin{array}{c}n^{\circ} \\
\text { Alumnes } \\
\text { ingerites }\end{array}$ & $\begin{array}{c}\text { n" } \\
\text { slumnos } \\
\text { rindicron } \\
\text { LT }\end{array}$ & retentelion & $\begin{array}{l}\text { \& } \\
\text { Aprobades } \\
\text { Final }\end{array}$ \\
\hline \multirow{2}{*}{ PEY2001 } & SPFC & $59 \%$ & 4,4 & 19 & 17 & $94 \%$ & $94 \%$ \\
\hline & PRES & $64 \%$ & 4,3 & 220 & 177 & $80 \%$ & $73 \%$ \\
\hline \multirow{2}{*}{ STr2001 } & SPFC & $95 \%$ & 4,9 & 23 & 20 & $97 \%$ & $87 \%$ \\
\hline & PRES & $94 \%$ & 4,8 & 258 & 210 & $92 \%$ & $80 \%$ \\
\hline \multirow{2}{*}{ SSY2001 } & SPFC & $100 \%$ & 6,0 & 21 & 20 & $95 \%$ & $95 \%$ \\
\hline & PRES & 85\% & 5,6 & 223 & 189 & $84 \%$ & $85 \%$ \\
\hline
\end{tabular}

Se realizó un piloto para la carrera Administración de Pedes Computacionales PEV con dos secciones en Viña del Mar:

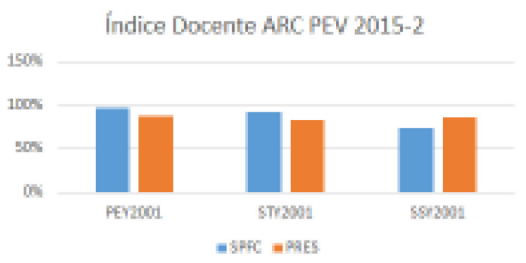




\section{Rendimiento de Asignatura 2015-1}
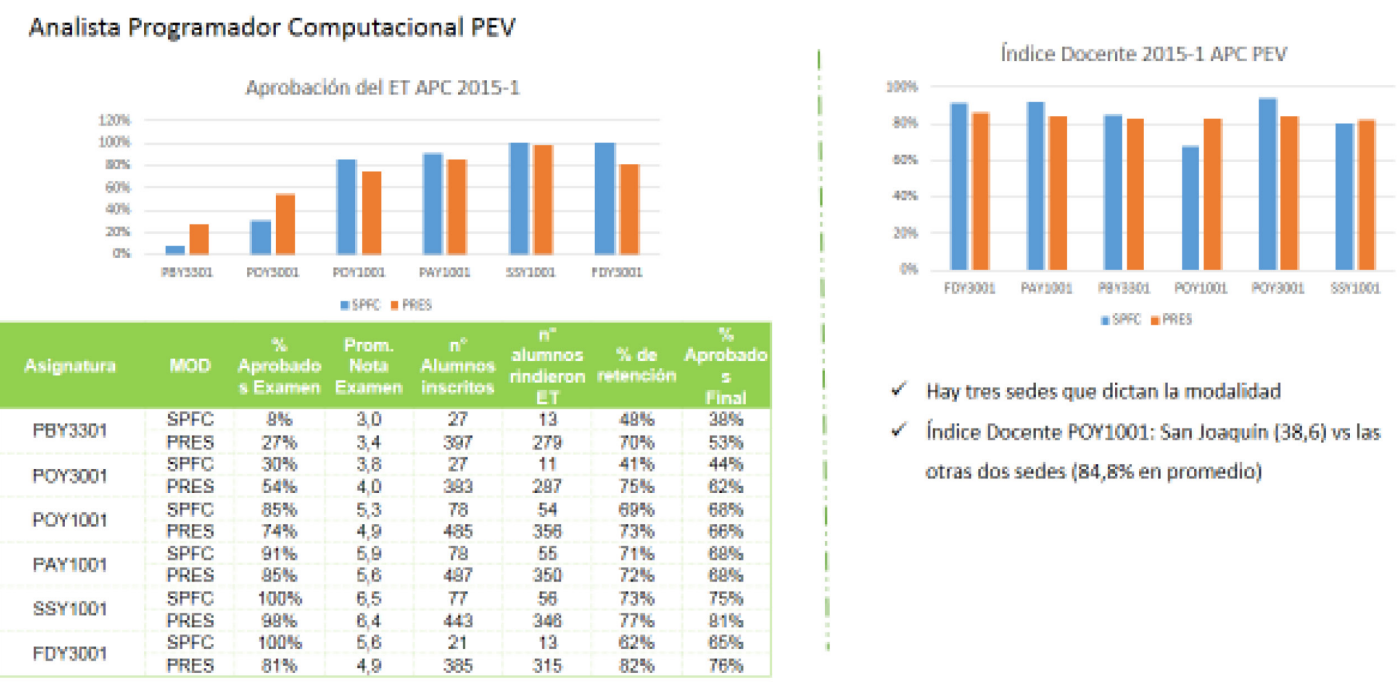

Rendimiento de Asignatura 2015-1

Administración de Redes Computacionales PEV

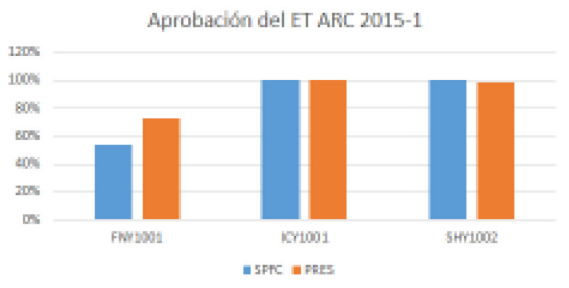

\begin{tabular}{|c|c|c|c|c|c|c|c|}
\hline Asignatura & WOD & $\begin{array}{c}\mathrm{x} \\
\text { Aprobados } \\
\text { Examen }\end{array}$ & $\begin{array}{l}\text { Prom. } \\
\text { Nota } \\
\text { Examen }\end{array}$ & $\begin{array}{c}n^{*} \\
\text { Numnos } \\
\text { inseritas }\end{array}$ & $\begin{array}{c}\mathrm{n}^{\mathrm{n}} \\
\text { sluminos } \\
\text { rindision } \\
\text { ET }\end{array}$ & $\begin{array}{l}\text { Se de } \\
\text { rebención }\end{array}$ & $\begin{array}{l}\text { Aprobsidoe } \\
\text { Finsl }\end{array}$ \\
\hline \multirow{2}{*}{ FWY1001 } & SPFC & $54 \%$ & 5,3 & 29 & 21 & $72 \%$ & $56 \%$ \\
\hline & PRES & $73 \%$ & 4,8 & 305 & 236 & $T 7 \%$ & $65 \%$ \\
\hline \multirow{2}{*}{ crtoo1 } & SPFC & $100 \%$ & 5,8 & 29 & 26 & $90 \%$ & $8 \%$ \\
\hline & PRES & $100 \%$ & 6,1 & 288 & 240 & $96 \%$ & $82 \%$ \\
\hline \multirow{2}{*}{ SHY1002 } & SPFC & $100 \%$ & 6,1 & 29 & 25 & $86 \%$ & $86 \%$ \\
\hline & PRES & $90 \%$ & 6,5 & 275 & 232 & $84 \%$ & $84 \%$ \\
\hline
\end{tabular}

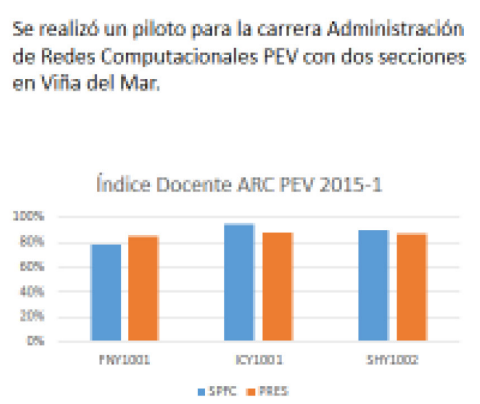

En cuanto a información cualitativa que se ha levantado desde las Sedes, a través de reuniones Focus Group aplicado a los estudiantes y docentes, podemos mencionar las principales manifestaciones:

Administración de Redes Computacionales PEV

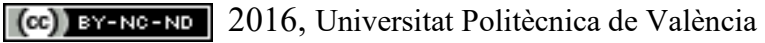


a) El alumno debe tomar un rol activo

b) Poca instrucción en uso del Ambiente Virtual de Aprendizaje (AVA-Blackboard) (para docentes y alumnos)

c) Los alumnos y docentes se han adaptado a la modalidad

d) Los docentes han desarrollado habilidades de gestión

e) La calidad del material es buena

f) El foro o alguna actividad síncrona podría ser una herramienta para el alumno

g) Los simuladores funcionan pero la experiencia con equipo real es motivante

h) Se requiere un buen equilibrio entre las actividades presenciales y no presenciales

i) Las asignaturas "teóricas" pueden ser más atractivas

j) El rol del docente es crítico

Analista Programador Computacional PEV

a) Falta de tiempo para la revisión de las experiencias no presenciales

b) Existen deficiencias en la calidad del material entregado

c) Deficiencias de la plataforma

\section{Conclusiones}

A la luz de los resultados observados hasta la fecha, en comparación con la modalidad tradicional, podemos afirmar que no existe perjuicio académico por el hecho de asistir presencialmente menos horas a la Institución. Los resultados de aprobación de los Exámenes Transversales, en general, son equivalentes a la modalidad tradicional, y en cuanto a la Aprobación Final (condición final de la asignatura que se obtiene como promedio ponderado entre el promedio de notas parciales (60\%) y nota de Examen Transversal (40\%)), la modalidad SPFC muestra leves mejoras respecto de la tradicional. Por lo que se puede concluir desde los datos, que la modalidad SPFC entrega niveles de flexibilidad al proceso formativo de manera eficiente, resguardando el éxito de los objetivos de aprendizaje suscritos en el perfil de egreso.

Adicionalmente, podemos afirmar que los alumnos están satisfechos con su modalidad, nos han mencionado, a través de Focus Group, que pese a los diversos problemas que han enfrentado, el material de aprendizaje es bastante intuitivo y cómodo para avanzar en su aprendizaje, por lo que les gusta mucho y valoran poder aprender de manera remota.

En resumidas cuentas, el modelo Flipped Classroom funciona y nos anima seguir desarrollando el modelo, escalándolo bajo estándares y procedimientos institucionales.

\section{Bibliografía}

- Álvarez Álvarez, B., González Mieres, C., \& García Rodríguez, N. (2007). La motivación y los métodos de evaluación como variables fundamentales para estimular el aprendizaje autónomo. REDU. Revista de Docencia Universitaria, 5(2), 1-13.

(c)) BY-NC-ND 2016, Universitat Politècnica de València

Congreso In-Red (2016) 
- Crome, K., Farrar, R., \& O’Connor, P. (2009). What is autonomous learning? Learning and Teaching in Philosophical and Religious Studies, 9(1), 111.

- Organización Internacional del Trabajo, OIT/Cinterfor, 2013

\section{Referencias Electrónicas}

- $\quad$ http://educalab.es/mooc

- $\quad$ https://es.khanacademy.org/about

- https://www.codeschool.com/

- www.openenglish.com/

- http://www.stackoverflow.com/

- http://www.theflippedclassroom.es/ 